\title{
Profissão docente: continuidades e regularidades na história desse ofício
}

\author{
Teaching profession: continuities and regularities
}

in the history of the profession

\author{
Angela Cristina Fortes lório ${ }^{1}$ \\ angela-iorio@hotmail.com
}

\section{Resumo}

Este texto foi construído como trabalho final da disciplina História da Profissão Docente, no Curso de Doutorado em Educação da PUC-Rio, com o objetivo de refletir sobre as transformações que vêm impactando a profissão docente e a imagem desse ofício no campo social. Alguns autores serviram de interlocutores teóricos, em especial, Dubet (2002), Mendonça e Cardoso (2007), Oliveira e Assunção (2009), Nóvoa (2009). A fragmentação da profissão, os baixos salários, o desprestígio, a má qualidade da formação, são alguns dos elementos que vêm impactando o trabalho docente e a imagem que o professor constrói de si mesmo e que integra a constituição de sua identidade profissional.

Palavras-chave: Trabalho docente, Desprestígio profissional, Cenário político, Formação docente, História

\begin{abstract}
This text was done as the final paper of the History of Teaching Profession course, in the doctoral programme in Education at PUC-Rio, aiming to reflect on the transformations that have been impacting the teaching profession and its image in the social field. Some authors have served as theoretical partners, in particular, Dubet (2002), Mendonça and Cardoso (2007), Oliveira and Assunção (2009), Nóvoa (2009). The fragmentation of the profession, the low wages, low status, the poor quality of training are some elements that are impacting the work of the professor and the image that the teacher constructs about himself and that integrates the constitution of their professional identity.

Keywords: Teaching work, Professional disfavor, Political scene, Teacher training; History
\end{abstract}

\footnotetext{
1 Doutoranda em Educação na Pontifícia Universidade Católica do Rio de Janeiro - PUC-Rio; Professora na Secretaria de Estado de Educação do Rio de Janeiro - SEEDUC-RJ; Professora Substituta da UERJ - Faculdade de Educação da Baixada Fluminense; Pesquisadora da Rede Latinoamericana de Estudos sobre Trabalho Docente - Rede ESTRADO
}

Revista Educação Online, n. 18, jan-mai 2015, p. 45-57 
Este trabalho é fruto das reflexões emanadas com as manifestações políticas que marcaram o ano de 2013, em conjunto com os textos estudados na disciplina História da Profissão Docente, ministrada pela professora Ana Waleska Mendonça, no Curso de Doutorado em Educação da PUC-Rio, com o objetivo de refletir sobre as transformações que vêm impactando a profissão docente e a imagem desse ofício no campo social. Alguns autores serviram de interlocutores teóricos, em especial, Dubet (2002), Mendonça e Cardoso (2007), Oliveira e Assunção (2009), Nóvoa (2009). O cenário político do Brasil tem mostrado o clamor por mudanças na cena política e social, trazendo à tona o discurso de valorização do professor e o resgate do prestígio profissional. A fragmentação da profissão, os baixos salários, o desprestígio, a má qualidade da formação, são alguns elementos que vêm impactando o trabalho docente e a imagem que o professor constrói de si mesmo e que integra a constituição de sua identidade profissional. A história da profissão docente é marcada por elementos que mantêm certas regularidades e continuidades. Refletir sobre essas questões amplia a compreensão desse ofício e do grau de complexidade crescente em termos de competências e habilidades que são exigidos do professor.

As manifestações noticiadas nos meios de comunicação, incluindo as redes sociais, refletem a emergência de maior investimento em saúde e educação, traduzida em um discurso de valorização profissional, através de salários dignos, como uma das formas de se resgatar o prestígio da categoria, que vem sendo desqualificada ao longo das últimas décadas, devido à má formação, ao processo de precarização do ofício, ao desprestígio social e, como consequência, tem sofrido os impactos da redução salarial.

Nas redes sociais ${ }^{2}$, cartazes fotografados nas manifestações, que ocorreram na cidade do Rio de Janeiro, no ano de 2013, exibiam a frase: "Professor, te desejo o salário de um deputado e o prestígio de um jogador de futebol." Imagens como essa evidenciam a perda de prestígio e a pouca

\footnotetext{
2 Facebook: um site e serviço de rede social que foi lançada em 04 de fevereiro de 2004, operado e de propriedade privada da Facebook Inc..
}

Revista Educação Online, n. 18, jan-mai 2015, p. 45-57 
valorização profissional do professor, uma profissão fragmentada, que vem sofrendo as influências do declínio do programa institucional (DUBET, 2002), como a maioria das profissões que trabalham com o outro, ou seja, as profissões que exigem maior competência relacional.

Essa inquietação e demanda do povo vêm de encontro às discussões trazidas por diversos autores a respeito dos desafios da profissão docente (HARGREAVES, 1998; CANÁRIO, 1997, 2001; MAROY, 2006; CAMPOS, 2007; OLIVEIRA; ASSUNÇÃO, 2009; FORMOSINHO, 2009; LESSARD, 2009), e enfatizados em diversos textos, sobre a gênese da profissão (MENDONÇA; CARDOSO, 2007), a profissionalização docente no Brasil (BUENO; BOSSOLO, 2011), a universalização da formação e o trabalho docente (NÓVOA, 2009), a feminização e feminilização do magistério (CARVALHO, 2005; BRUSCHINI; AMADO, 2011), autobiografias de professoras (MIGNOT, 2003), o declínio do programa institucional (DUBET, 2002), as imagens de professores (NÓVOA, 2009).

Na pesquisa realizada pela Unesco sobre o desafio da profissionalização docente no Brasil e na América Latina, a pesquisadora equatoriana Magali Campos (2007, p. 17) afirmou que:

A profissão docente deve ser vista numa perspectiva integral. Para tanto, é preciso recuperar o prestígio da carreira e o valor que os bons docentes têm para o país e seu desenvolvimento. É preciso colocar a profissão docente como tema central de política pública e educacional e como prioridade na agenda dos governos. Por fim, há que investir e investir bem no fortalecimento da profissão docente. Por outro lado, ver a profissão docente numa perspectiva integral significa reconhecer os múltiplos fatores que influenciam no desempenho profissional docente, tais como: formação inicial, formação continuada em serviço, avaliação de desempenho, condições de trabalho, salários, cultura organizacional, reconhecimento social, saúde etc. Portanto, o fortalecimento e o desenvolvimento da profissão numa perspectiva integral, devem envolver igualmente múltiplos atores e setores: educação, finanças, saúde, parlamento, meios de comunicação, organização e movimentos sociais.

Enfim, à luz desse repertório teórico e das discussões suscitadas por esses autores, pretendo construir este texto, com o objetivo de refletir a respeito da história desse ofício, marcado por períodos de continuidades e regularidades,

Revista Educação Online, n. 18, jan-mai 2015, p. 45-57 
que são observadas desde a reforma pombalina (MENDONÇA; CARVALHO, 2007).

O professor, um profissional que trabalha com o outro, é impactado em sua prática pelos moldes em que a sociedade está estruturada, pelas transformações na vida social influenciadas pelo espírito capitalista, pela perda da unidade e de valores, pela exigência de eficácia profissional e de organizações mais hábeis e mais complexas (DUBET, 2002, p. 14-15). Movidos pelas influências da pós-modernidade, pelo sentimento de desencantamento e pelo crescente ceticismo em relação aos valores fundamentais da modernidade, os docentes se submetem à lógica do sistema e são manipulados por um modelo pedagógico mercadológico, tanto no sistema público como no privado, que exige eficácia e bons resultados.

Como afirma Fridman (2000), as transformações trazidas pela pósmodernidade não são percebidas somente na esfera da cultura e da economia, mas afeta outros campos, como, da educação, da filosofia, das artes, da política etc.

O trabalho docente vem se intensificando, exigindo que os professores suportem maiores pressões e respondam a cada dia com maiores esforços. Segundo Hargreaves (1998, p. 132), "os professores são retratados como sendo gradualmente controlados por programas prescritos, currículos obrigatórios e métodos de instrução minuciosamente programados."

Muitas vezes confundida com profissionalismo, a intensificação do trabalho docente mostra, na realidade, a perversidade de um sistema, formatado num modelo empresarial de educação.

Retomando a minha dissertação de mestrado $^{3}$, pude evidenciar o quanto esse modelo de sociedade, voltado para o lucro e a eficácia, leva o professor a se tornar um mero repetidor de conteúdos, desprovido de autonomia, do poder

\footnotetext{
${ }^{3} \mathrm{~A}$ investigação incidiu, particularmente, sobre as condições de trabalho das professoras e em como se processava o desenvolvimento profissional. O grupo pesquisado era constituído de oito professoras do primeiro segmento do ensino fundamental, na faixa etária que variava entre 27 e 39 anos de idade. A escola estudada estava localizada na zona norte da cidade do Rio de Janeiro e atendia aos alunos da "nova classe média" (termo utilizado por SOUZA; LAMOUNIER, 2010).
}

Revista Educação Online, n. 18, jan-mai 2015, p. 45-57 
de criação, renunciando à sua autoridade pedagógica, num exercício acrítico da profissão. Essa cultura institucional performática afeta profundamente a percepção que os indivíduos têm de si mesmos e do próprio valor e impacta a forma como as relações se estabelecem no interior das instituições, estimulando o individualismo e a competitividade.

Segundo Ball (2004), a 'performatividade' tem impactado as relações em diferentes espaços profissionais, por alterar a autoimagem, a carreira e o entrosamento da equipe. $O$ efeito da cultura do lucro gera um sentimento de competitividade, classificando os indivíduos de acordo com o desempenho, gerando sentimentos de orgulho, culpa, vergonha, inveja e alterando a forma como as relações se estabelecem no interior das instituições, estimulando o individualismo e a competitividade.

No entanto, em termos gerais, os professores acabam inseridos na performatividade pelo empenho com que tentam corresponder aos novos (e às vezes inconciliáveis) imperativos da competição e do cumprimento de metas. [...]. O professor, o pesquisador e o acadêmico estão sujeitos a uma miríade de julgamentos, mensurações, comparações e metas. Informações são coletadas continuamente, registradas e publicadas com frequência na forma de rankings. O desempenho também é monitorado por análises dos pares, visitas locais e inspeções. (BALL, 2004, p. 548-549)

Uma das professoras que entrevistei durante a pesquisa de mestrado, professora Leandra, deixou evidente em sua fala o mal-estar que sentia em relação às condições de trabalho, à insatisfação com o salário e ao desprestígio da profissão:

O que nos assusta é a falta de valorização que a profissão vem recebendo por parte da sociedade caótica que temos vivido, os baixos salários, a falta de prestígio [...]. Creio que muita coisa deve ser repensada, mudada, para que a instituição escolar saia dessa passividade. ("referência excluída para assegurar anonimato")

Os diários de campo examinados por Mignot (2003, p. 144-145), também apresentam e evidenciam as queixas das professoras com os baixos salários e as extensas jornadas de trabalho. As docentes, do início do século $X X$, enfrentavam resistências e críticas dos diretores das escolas onde lecionavam, sendo muitas vezes hostilizadas pelos gestores, e vivenciavam a relação de 
poder no espaço profissional. As histórias de vida dessas professoras reforçam a imagem de que o exercício profissional exigia sacrifícios e muita dedicação. Hoje, essa ainda é a realidade da profissão docente.

\section{As continuidades e regularidades na história da profissão docente}

As reformas pombalinas dos estudos menores, segundo Mendonça e Cardoso (2007), impactaram o processo de profissionalização dos professores e foi um momento decisivo para a história da profissão docente. A intervenção do Estado na constituição do magistério como profissão influenciou a forma como o ofício docente se organiza até os dias atuais.

A distinção entre mestres de ler, escrever e contar ${ }^{4}$ e os professores régios de gramática latina, grego, retórica e filosofia ${ }^{5}$ marca a profissão desde esse período e promove uma hierarquização do magistério, percebida nas diferentes definições de professores: professor (anos iniciais), professores licenciados ( $2^{\circ}$ segmento do fundamental e ensino médio) e professores universitários (que também se distinguem de acordo com o sistema de ensino).

As autoras enfatizam ainda que as desigualdades inerentes aos distintos grupos de docentes (mestres e professores) estão na gênese da constituição da profissão docente, que promoveu e fortaleceu clivagens internas que diferenciam os docentes por formação, nível de ensino em que atuam, faixa salarial, dentre outras. Clivagens essas, observadas nos salários distintos dos professores, condições de trabalho, formação e segmento de ensino em que lecionam ainda nos dias de hoje.

O final do século XIX marca a aquisição pelos professores de um novo estatuto profissional. Inicia-se a formação nas escolas normais e a edificação de sistemas públicos de ensino. No século $\mathrm{XX}$, a expansão das escolas de massa trouxe transformações sociais e políticas, exigindo maior competência profissional, em relação à formação, preferencialmente em nível superior. "Esse

\footnotetext{
4 Os professores primários, atuais professores dos anos iniciais $\left(1^{\circ}\right.$ ao $5^{\circ}$ anos do ensino fundamental).

${ }^{5}$ Atualmente associados aos professores do segundo segmento do ensino fundamental e ensino médio.
}

Revista Educação Online, n. 18, jan-mai 2015, p. 45-57 
seria também um passo relevante para se obter o status profissional e recuperar a suposta perda de conhecimento em razão da queda de qualidade de ensino dos Cursos Normais [...]." (BUENO; BOSSOLO, 2011, p. 268).

Exigia-se do professor: novos saberes, o conhecimento acadêmico era cada vez mais valorizado, novas técnicas foram legitimadas pela tecnicização e houve maior controle da prática docente na rede pública de ensino.

Na França, com a expulsão dos jesuítas do sistema educacional, houve a necessidade de admissão de docentes nas universidades públicas, em especial, para lecionar as novas disciplinas que surgiam ao final da $2^{\underline{a}}$ Guerra Mundial, dentre elas, a psicologia, a sociologia, a linguística. Para suprir a demanda, ingressaram nas universidades professores sem a formação de excelência oferecida pela École Normale Supérieure de Saint-Cloud e Rue D'Ulm ${ }^{6}$ A necessidade de suprir a demanda nas cadeiras universitárias e a intensa massa de jovens que ingressavam nas universidades determinou a admissão de professores com baixa formação, sem doutoramento, o que, consequentemente, impactou a qualidade da formação dos egressos dos cursos superiores em Paris, em especial, os das novas disciplinas. Nas disciplinas canônicas (línguas antigas, história, filosofia, literatura), continuavam lecionando os professores catedráticos, como afirma Bourdieu (2013).

Durante a década de 1970, como enfatizam Bossolo e Bueno (2011), iniciou-se o processo de proletarização do trabalho docente, que se refletia nos

\footnotetext{
${ }^{6}$ É uma grande e prestigiosa escola de formação de professores, considerada uma instituição de excelência, aonde foram formados os grandes pensadores $e$ intelectuais da contemporaneidade, como Foucault, Chartier, Sartre, Comte, Bourdieu, Simone de Beauvoir, dentre outros. O campus principal está situado na rue d'Ulm, no $5^{\circ}$ arrondissement de Paris. É vinculada diretamente ao Ministério do Ensino Superior e da Pesquisa da França. A escola reunia efetivamente professores particularmente brilhantes, marcados pelo espírito do lluminismo francês.

7 O objetivo de Bourdieu com este estudo, realizado em 1984, período de profundas transformações sociais na Europa após o Movimento de Maio de 1968, foi apreender o mundo universitário, que, tal qual o campo social, é permeado por múltiplas produções culturais, trajetórias sociais e escolares de seus agentes, produção científica e disputas de poder. Foi realizado um trabalho denso de pesquisa com professores universitários parisienses, que contou com a colaboração de um grupo de pesquisadores, dentre eles Yvete Delsaut, a quem Bourdieu fez um agradecimento especial no livro. Os anexos às pp. 249-286 apresentam o minucioso estudo realizado pelo autor e sua equipe.
}

Revista Educação Online, n. 18, jan-mai 2015, p. 45-57 
salários, que sofreram uma queda substancial de 1967 a 1979. Os saberes da ciência foram privilegiados em detrimento dos saberes da experiência, os livros didáticos eram produzidos maciçamente com orientações para os professores (manuais), as salas de aulas foram invadidas por especialistas que destituíam o professor de sua autonomia pedagógica. Assim, segundo essas autoras, "as ciências da educação foram usadas não só para desvalorizar os saberes da prática, mas também para desvalorizar as próprias professoras." (BOSSOLO; BUENO, 2011, p. 268)

As inovações, junto com uma proposta de desenvolvimento e democratização do ensino, também trouxeram perda de status e um achatamento salarial. Como afirmam as autoras, essas medidas desenvolvimentistas submeteram as professoras ao controle, mensurado por "formulários, relatórios e gráficos", houve o fracionamento da categoria docente e, consequentemente, a proletarização da profissão.

A história da profissão docente é marcada por elementos que constituíram esse ofício e mantém certas regularidades e continuidades. A imagem da docência como vocação, como profissão que exige sacrifícios, doação, amor, resignação, boa conduta, ainda é presente no discurso pedagógico atual. Essa imagem da profissão, como doação e vocação, tem impactos na maneira como a sociedade e as políticas públicas percebem esse profissional, valorizam-no e o remuneram. É comum, no discurso do senso comum, ouvir estas frases: "professor trabalha por amor e não por dinheiro", ou ainda, "quem quer dar aula, faz isso por gosto, e não pelo salário".

O fato de a escola estar submetida a um novo conjunto de demandas sociais faz com que o trabalho do professor passe a se inscrever em um novo quadro de relações, exigindo um grau de complexidade crescente em termos de competências e habilidades. O professor deixa de ser um mero transmissor de informações/conhecimentos e passa a fazer parte de uma cultura interativa e de resolução de problemas. Esses fatores por si só impõem aos professores exigências, em termos do exercício do seu ofício, que extrapolam a esfera propriamente técnico-profissional. 
Uma profissão que trabalha com o outro, que se constitui nas relações e interações, que é perpassada por afetos e desafetos, gera, consequentemente, um tênue estreitamento em relação à esfera do privado e familiar. As atribuições do professor se confundem com responsabilidades que devem ser atribuídas à família, à comunidade local, às associações culturais, às igrejas, aos centros de saúde etc.

É nesta perspectiva que a proposta adquire todo seu sentido, abrindo para a possibilidade de um novo contrato educativo, cuja responsabilidade é partilhada por um conjunto de actores e de instâncias sociais, não ficando apenas nas mãos dos educadores profissionais. Se é verdade que a escola cumpriu, ao longo do século XX, um importantíssimo trabalho social, não é menos verdade que hoje se torna essencial evoluir no sentido de uma maior responsabilidade da sociedade. (NÓVOA, 2009, p. 87)

O trabalho interativo, que caracteriza o magistério, transforma dialeticamente não apenas o estudante, mas igualmente o professor. Esse tipo de trabalho levanta as questões complexas do poder, da afetividade e da ética, que são inerentes à interação humana, à relação com o outro. É perpassada por fortes mediações simbólicas entre os agentes e exige dos trabalhadores competências reflexivas e relacionais, além de capacidades profissionais para gerir interações e aprendizagens.

\section{Formação: um caminho para o resgate do prestígio profissional?}

A imagem que o professor constrói de si mesmo e integra a constituição de sua identidade profissional é compreendida também pelo processo de formação. Enfim, todas as experiências, os valores, as expectativas diante da atividade profissional, suas reflexões sobre a prática pedagógica são alavancadas pelos saberes, construídos na formação inicial e continuada, e contribuem para a construção da identidade profissional docente e para o seu desenvolvimento profissional.

Segundo Carvalho (2005), nos relatos dos professores pesquisados para sua tese de doutorado, foi enfatizada a importância da prática em seus processos de formação, assim como a troca de experiências com seus pares. Para Dubet e Martuccelli (apud CARVALHO, 2005, p. 96), 
os professores tendem a afirmar a superioridade da experiência sobre qualquer outra formação, porque é, sobretudo face a face com a classe, que se constrói sua identidade, e é na relação com as crianças, núcleo de sua experiência profissional, que se define o métier.

Algumas vezes, a característica relacional da profissão, no âmbito do trabalho docente, se opõe ao profissionalismo e evidencia uma faceta da construção social e histórica, em relação ao gênero feminino e masculino, e de como os atributos de masculinidade e feminilidade estruturam a maneira de pensar e fazer o trabalho docente na escola, especialmente, com crianças das séries iniciais do ensino fundamental, além de mascararem a necessidade de formação. Com a feminização e feminilização do magistério, parece que o afeto pode dar conta de todos os atributos necessários ao bom professor.

Para Dubet (2002), o professor tende cada vez mais a recorrer à sua personalidade, ao seu jeito de ser, para dar conta dos desafios impostos pela escola, visto que a formação profissional e as competências inerentes à profissão não o preparou para o exercício do ofício. Alguns autores consideram a ausência de formação uma das dimensões responsáveis pela precarização do trabalho docente e um dos elementos responsáveis pela perda de prestígio da profissão. Logo, iniciativas de formação continuada dos professores em exercício são alternativas de valorização do magistério e determinantes no desenvolvimento profissional docente.

Nas sociedades contemporâneas, o prestígio de uma profissão mede-se, em grande parte, pela sua visibilidade social. No caso dos professores, estamos mesmo perante uma questão decisiva, pois a sobrevivência da profissão depende da qualidade do trabalho interno nas escolas, mas também da sua capacidade de intervenção no espaço público da educação. (NÓVOA, 2009, p. 18)

Nesse sentido, a formação é um dos elementos constitutivos do desenvolvimento profissional que interfere no crescimento dos professores, em sua prática pedagógica e em sua função como docente. Devemos considerar que esse processo de formação docente é permanente e agrega uma série de elementos que colaboram para a definição da identidade profissional. Enfim, podemos afirmar que a despeito de todas as inovações tecnológicas e de todos 
os preceitos de racionalização, teorização e problematização do ensino, nada substitui um bom professor.

\section{À guisa da conclusão}

Visivelmente, estamos diante de uma realidade, em que a escola e o professor foram convocados a exercer, na sociedade contemporânea, inúmeras funções e/ou papéis, em função da ausência ou ineficiência de outras instituições, em virtude do declínio do programa institucional (DUBET, 2002). Ao professor, são atribuídas as funções de educar, cuidar, formar, logo, não é mais o estatuto profissional que define o papel a ser desempenhado pelo professor, mas sua personalidade, o seu jeito de ser, a sua competência relacional. Para Dubet (2002), não se trata de negar os conhecimentos que o docente deve possuir, mas de pensar o conceito de competência como uma síntese prática e interiorizada de todas as dimensões que constituem as suas experiências.

Nóvoa (2009), em seu livro Imagens do futuro presente elenca cinco facetas que definem o "bom professor": o conhecimento, que está atrelado à construção de práticas docentes que conduzam à aprendizagem dos alunos; a cultura profissional, que é incorporada na relação com os pares e na prática reflexiva; o tato pedagógico, que compreende a capacidade de relação e de comunicação do professor; o trabalho em equipe, que implica em um reforço das dimensões coletivas e colaborativas do trabalho em equipe; e o compromisso social, que convergem no sentido dos princípios, dos valores, da inclusão social, da diversidade cultural. Segundo ele, essas disposições são necessárias ao trabalho pedagógico.

Incluo mais uma que considero essencial e complementar a essas disposições, a formação do professor. Sem as bases teóricas, não é possível uma prática e práxis educativa; a formação e o diálogo permanente entre teoria e prática construirão os alicerces para a constituição de um bom professor, o que, consequentemente, promoverá uma ascensão profissional, o resgate do prestígio outrora perdido, uma valorização da profissão e, certamente, melhores salários.

Revista Educação Online, n. 18, jan-mai 2015, p. 45-57 
Encerro este trabalho, com a afirmação de Nóvoa (2009, pp. 68-69): "Precisamos de vistas largas, de um pensamento que não se feche nem nas fronteiras do imediato, nem na ilusão de um futuro mais-que-perfeito".

\section{Referências bibliográficas:}

BALL, Stephen J. Performatividade, privatização e o pós-estado do bem-estar. Educação \& Sociedade, Campinas, v. 25, n. 89, p. 1105-1126, set./dez. 2004. Dossiê: Globalização e Educação: Precarização do Trabalho Docente - Il. Disponível em: <http://www.cedes.unicamp.br>. Acesso em: 20 dez. 2014

BOURDIEU. Pierre. Homo academicus. 2ªed. Florianópolis: UFSC, 2013.

BRUSCHINI, Cristina; AMADO, Tina. Estudos sobre a mulher e educação: algumas questões sobre o magistério. Cadernos de Pesquisa, São Paulo, n. 64, p. 04-13, fev. 1988. Disponível em: <http://educa.fcc.org.br>. Acesso em: 20 dez. 2014.

BUENO, B. O.; SANTOS-BOSSOLO, E. P. dos. O trabalho docente em tempos de transição: A experiência de professoras primárias no estado de São Paulo (1960-1980). In: SIMÕES, R. H. S.; CORREA, R. L. T.; MENDONÇA, A. W. P. C. (Orgs.). História da profissão docente no Brasil. Vitória: Edufes, 2011. v. 7. p. 257-284.

CAMPOS, Magaly R. Profissão docente: novas perspectivas e desafios no contexto do século XXI. In: UNESCO. O desafio da profissionalização docente no Brasil e na América Latina. Brasilia: Consed; Unesco: 2007.

CANÁRIO, Rui. (Org.). Formação e situações de trabalho. Porto: Porto, 1997.

. A prática profissional na formação de professores. In: CAMPOS, Bártolo P. (Org.). Formação profissional na formação de professores. Porto: Porto, 2001.

CARVALHO, Marília Pinto de. Gênero na análise sociológica do trabalho docente: um palco de imagens. In: PEIXOTO, Ana Maria Casasanta; PASSOS, Mauro (Orgs). A escola e seus atores: educação e profissão docente. Belo Horizonte: Autêntica, 2005.

DUBET, François. Le déclin de l'institution. Paris: Édition du Seuil, 2002.

FORMOSINHO, João. (Org.) Formação de professores: aprendizagem profissional e acção Docente. Porto: Porto, 2009.

FRIDMAN, Luiz C. Vertigens pós-modernas: configurações institucionais contemporâneas. Rio de Janeiro: Relume-Dumará, 2000.

HARGREAVES, Andy. Os professores em tempos de mudança: o trabalho e a cultura dos professores na Idade Pós-moderna. Lisboa: Mc Graw-Hill, 1998.

Revista Educação Online, n. 18, jan-mai 2015, p. 45-57 
LESSARD, Claude. O trabalho docente, a análise da actividade e o papel dos sujeitos. Sísifo Revista de Ciências da Educação, n.9, p. 119-128, mai./ago. 2009. Disponível em: <http://sisifo.fpce.ul.pt>. Acesso em: 15 nov. 2014.

MAROY, Christian. Note de synthèse - Les évolutions du travail enseignant en France et en Europe: facteurs de changement, incidances et résistances dans l'enseignement secondaire. Revue Française de Pédagogie, n. 155, p. 111-142, avril-mai-jui 2006.

MIGNOT, Ana C. V. Em busca do tempo vivido: autobiografias de professoras. In: MIGNOT, Ana C. V; CUNHA, Maria T. S. (Orgs.). Práticas de Memória Docente. São Paulo: Cortez, 2003. p. 135-148.

MENDONCCA, A. W. P.; CARDOSO, T. M. R. F. L. A gênese de uma profissão fragmentada. Revista Brasileira de História da Educação, v. 7, n. 3 [15], p. 31 52, 2007. Disponível em: http://www.rbhe.sbhe.org.br. Acesso em: 23/04/2013.

NÓVOA, António. Professores: imagens do futuro presente. Lisboa: Educa, 2009.

OLIVEIRA, Dalila A.; ASSUNÇÃO, Ada Á. Intensificação do trabalho e saúde dos professores. Educação \& Sociedade, v. 30, n.107, p. 349-372, maio/ago. 2009. Disponível em: <http://www.cedes.unicamp.br>. Acesso em: 20/04/2014. 